\title{
Dental Treatment with a Gold Alloy Cast Crown for Severe Lumbago
}

\author{
Yoshiro Fujii \\ Shin Kobe Dental Clinic, Kobe, Japan \\ Email: shin-kobe-dentalclinic@s9.dion.ne.jp
}

How to cite this paper: Fujii, Y. (2019) Dental Treatment with a Gold Alloy Cast Crown for Severe Lumbago. Open Journal of Stomatology, 9, 21-27. https://doi.org/10.4236/ojst.2019.92003

Received: January 8, 2019

Accepted: January 30, 2019

Published: February 2, 2019

Copyright () 2019 by author(s) and Scientific Research Publishing Inc. This work is licensed under the Creative Commons Attribution International License (CC BY 4.0).

http://creativecommons.org/licenses/by/4.0/

\begin{abstract}
The patient was a 41-year-old woman experiencing severe lumbago for several years. The physician-in-charge referred her for dental treatment because examination did not reveal any specific abnormality in her lower back. Prior to the treatment, the patient could barely bend forward and backward because of serious back pain. Her body flexibility and lower back pain improved when a gold alloy cast crown was placed near her feet. However, when the crown was covered with aluminum foil, it was again very difficult for her to bend her body forward and backward. These results suggested that her body reacted positively because good electromagnetic waves emitted by the crown were absorbed by the body. The alloy used to make the crown was chosen using the Bi-Digital O-Ring Test. Moreover, the shape, contact strength, and occlusion (biting condition) of the crown were also determined by the Bi-Digital O-Ring Test. After the crown was placed on her upper right first molar, her lumbago completely disappeared and did not recur for $>5$ years of follow-up. The effectiveness of electromagnetic waves on the condition of the body, as in this case, has not often been acknowledged in modern medicine, and the underlying mechanism remains unclear; therefore, further research is required.
\end{abstract}

\section{Keywords}

Electromagnetic Waves, Metal Crown, Bi-Digital O-Ring Test, Lumbago (Lower Back Pain)

\section{Introduction}

There is a close relationship between the dental and whole-body conditions. Studies have shown that oral conditions, especially occlusion, are closely associated with other parts of the body, for example, body posture, temporomandibular disorder, and cervicobrachial issues [1] [2] [3] [4]. The author has also re- 
ported on the relationship of occlusion [5] [6] and shape [7] of the tooth with the whole-body condition. Moreover, the author has reported on the relationship between electromagnetic waves and systemic conditions affecting the body [8]-[16] and intractable dermatitis owing to dental metal [17] [18]. Lumbago is a very common condition, but some cases are intractable. This case report demonstrates that dental treatment with a metal crown for intractable lumbago after a variety of nonsurgical treatments, including medical treatment, is not effective.

\section{Case Report}

\subsection{Patient and Methods}

Patient and chief complaint: The patient was a 41 -year-old woman. She had been experiencing severe lumbago for several years.

\subsection{Case History}

The patient underwent a variety of nonsurgical orthopedic treatments and massage to treat her lumbago. However, no treatment was found to be effective; therefore, the physician-in-charge referred the patient to the author's dental clinic for dental treatment.

\subsection{Medication}

She was taking pravastatin sodium (product name: Mevalotin) for hyperlipidemia.

\subsection{Present Status}

The patient could barely bend forward and backward at the waist because of sharp pain in her lower back (Figure 1). There were no abnormal views which should be reported in anything but hyperlipidemia, and there wasn't also a subjective symptom besides the lumbago.

\subsection{Treatment}

A gold alloy metal crown (87\% gold, $10.6 \%$ platinum, and $0.4 \%$ zinc and iridium) was placed on her upper right first molar (Figure 2) and was judged to be effective by the Bi-Digital O-Ring Test [19] [20].

\section{Results}

When the crown was placed on the floor in front of the patient's feet after form correction and occlusal adjustment was complete, she could bend forward and backward very easily, and her lumbago was markedly reduced (Figure 3). When the crown was covered with aluminum foil, the symptoms recurred, and it became very difficult for her to bend her body (Figure 4). When the aluminum foil was removed, she could easily bend forward and backward again. After the crown was placed in her mouth with glass ionomer cement (Figure 5), her lum- 
bago completely disappeared. Her flexibility was more improved (Figure 6) than that when the crown was placed on the floor in front of her feet (Figure 3). The patient's condition was followed for approximately 5 years after the crown had been placed. During this period, her lumbago did not recur, and she did not seek any additional treatment.

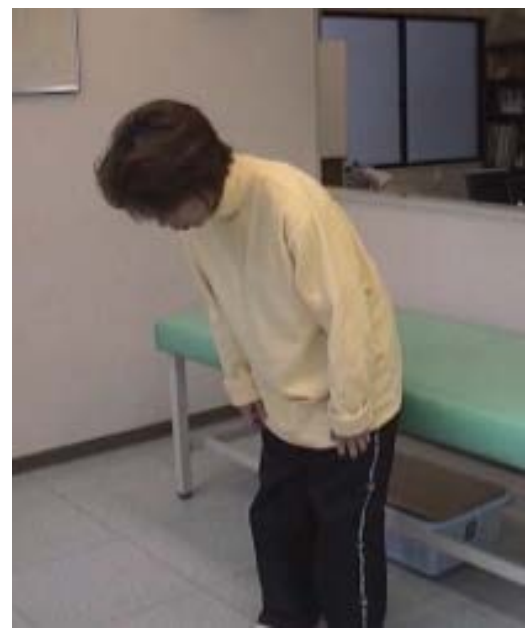

Figure 1. The patient had been experiencing severe lumbago for several years and could barely bend forward and backward.

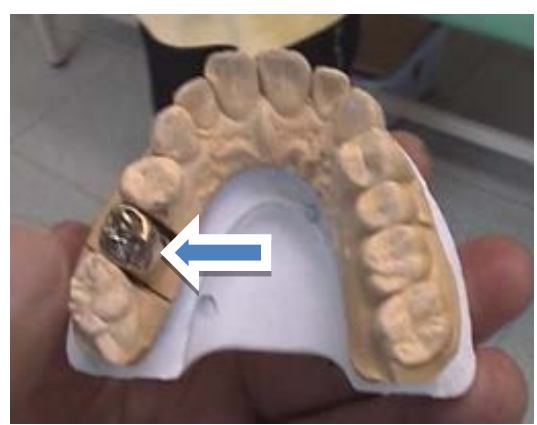

Figure 2. A gold alloy metal crown was made for her upper right first molar prosthesis (arrow).

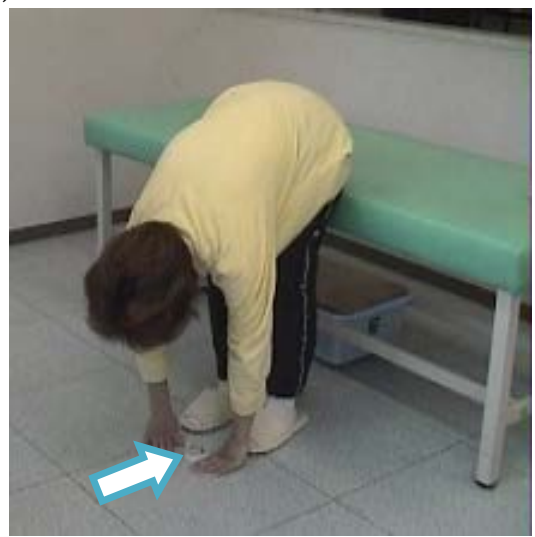

Figure 3. As soon as the gold alloy metal crown was placed on the floor in front of her feet (arrow), the patient was able to bend forward and backward very easily, and her lumbago was markedly reduced. 


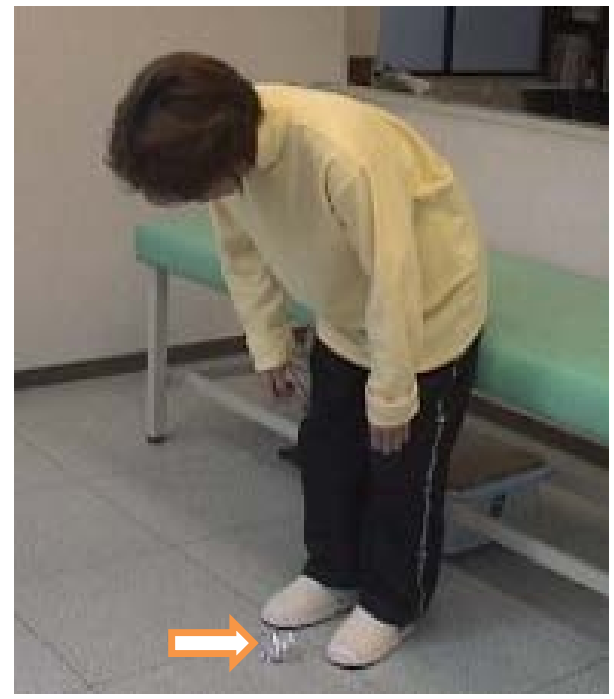

Figure 4. The patient was unable to bend forward normally after the crown was covered by aluminum foil (arrow).

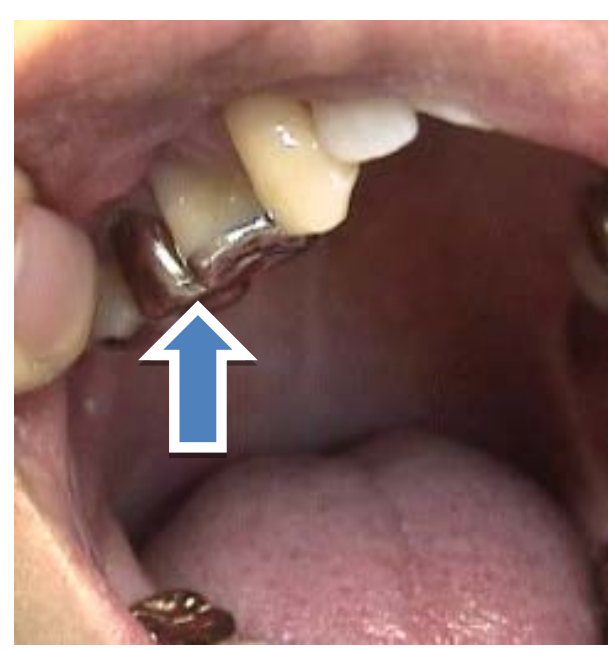

Figure 5. The crown was placed in the patient's mouth (arrow).

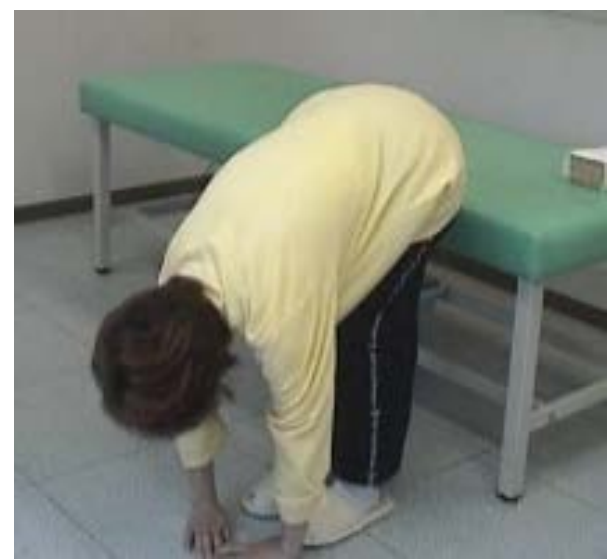

Figure 6. The patient was able to fully bend forward and backward after placing the crown in her mouth. Her flexibility was better than that when the crown was placed on the floor in front of her feet (Figure 3). 
To see the actual experiment described in this case, please visit the YouTube video:

"Lumbago improves by simply placing a crown near foot"

https://www.youtube.com/watch?v=FoTSWuVw24s\&list=UUqAoDvLMJAJ-

H-HLCF4V8-A

(last checked: 1 Jan 2019).

\section{Discussion}

The results of this study show that even if the crown is not placed in the body, it can have a marked effect on joint mobility when it is placed near the body. Simply having the substance near the body can influence a patient's condition. This influence may be due to the electromagnetic waves emitted by the substance. The author has previously suggested that this effect should be termed as indirect effect [21] [22]. Therefore, the outcome of placing the crown may be due to normal or corrected occlusion, contact with the adjacent tooth, and electromagnetic waves (indirect effect). Modern western medicine ignores the indirect effect; however, it can have serious implications for the accuracy of the testing of materials. The results of this study demonstrated that the crown could affect the severity of lumbago when placed in the oral cavity and near the body. It has been hypothesized that electromagnetic waves have played a role in improving the lumbago when the alloy cast crown was placed near the body. Since there was no abnormality in her lower back with medical check like X-ray image and also a variety of nonsurgical orthopedic treatments and massage was ineffective, the author judged that lumbago might be caused by brain malfunction. There are reports that electromagnetic waves influences cerebral bloodstream [23] [24] [25]. The author hypothesize that when the crown approached a body, the subject's cerebral bloodstream was improved by electromagnetic waves mitted by the crown. As a result, her brain function might be improved. However, the real underlining mechanism is still unclear, and further research is warranted. The Bi-Digital O-Ring Test may catch the electromagnetic waves, which these material rise from, and it is thought that this influence on the body can be evaluated. In the field of dentistry, the use of the Bi-Digital O-Ring Test may have an impact on the choice of dental material, crown restoration, form of the dental prosthesis, judgment of the contact strength with the adjacent tooth, and occlusion state. Even if a substance doesn't enter but approaches a body, it will influence on a body. Therefore, we should understand from this case that it's necessary to consider the influence of ornaments, clothes and a cell phone etc. which approaches the body on the body. When the unpleasant symptom disappears when they approach the body like this case, the substance can be recommended to approach a body. However, if the unpleasant symptom occurs, when it approaches the body, it's better to avoid the substance from a body.

\section{Conclusion}

The patient had been experiencing severe lumbago for several years, and she 
could barely bend forward and backward before treatment because of back pain. She showed remarkable improvement when a gold alloy metal crown was placed in front of her feet. When the crown was covered with aluminum foil, it was again very difficult for her to bend her body. It was suggested that her body showed a positive reaction because it absorbed good electromagnetic waves emitted by the crown. The impact of placing a crown included not only recovering normal occlusion and contact with adjacent teeth but also receiving electromagnetic waves emitted by the crown. However, the underlining mechanism is still unclear, and further research is required. The Bi-Digital O-Ring Test may react to the uptake of electromagnetic waves from the crown, and this test may be used to evaluate the influence of substances on the body.

\section{Acknowledgements}

This patient agreed for her case to be reported.

\section{Conflicts of Interest}

The author declares no conflicts of interest regarding the publication of this paper.

\section{References}

[1] Watanabe, E.K., Yatani, H., Kuboki, T., Matsuka, Y., Terada, S., Orsini, M.G., et al. (1998) The Relationship between Signs and Symptoms of Temporomandibular Disorders and Bilateral Occlusal Contact Patterns During Lateral Excursions. Journal of Oral Rehabilitation, 25, 409-415. https://doi.org/10.1046/j.1365-2842.1998.00262.x

[2] Karppinen, K., Eklund, S., Suoninen, E., Eskelin, M. and Kirveskari, P. (1999) Adjustment of Dental Occlusion in Treatment of Chronic Cervicobrachial Pain and Headache. Journal of Oral Rehabilitation, 26, 715-721. https://doi.org/10.1046/j.1365-2842.1999.00448.x

[3] Sakaguchi, K., Mehta, N.R., Abdallah, E.F., Forgione, A.G., Hirayama, H., Kawasaki, T., et al. (2007) Examination of the Relationship between Mandibular Position and Body Posture. CRANIO, 25, 237-249. https://doi.org/10.1179/crn.2007.037

[4] Gangloff, P., Louis, J.P. and Perrin, P.P. (2000) Dental Occlusion Modifies Gaze and Posture Stabilization in Human Subjects. Neuroscience Letters, 293, 203-206. https://doi.org/10.1016/S0304-3940(00)01528-7

[5] Fujii, Y. (2015) Orthodontic Treatment to Improve Hip Joint Mobility and Balance. Journal of Dentist, 3, 29-32. https://doi.org/10.12974/2311-8695.2015.03.01.5

[6] Fujii, Y. (2016) Two Cases of Severe Dementia Showing Dramatic Improvement after Denture Placement. Advances in Alzheimer's Disease, 5, 46-52. https://doi.org/10.4236/aad.2016.52004

[7] Fujii, Y. (2015) Dental Stimulation to the Buccal Mucous Membrane Cases Lumbago: A Report of Two Cases. Case Reports in Clinical Medicine, 4, 289-296. https://doi.org/10.4236/crcm.2015.48058

[8] Fujii, Y. (2007) The Dental Treatment That Used Environment of Electromagnetic Wave. Acupuncture and Electro-Therapeutics Research, 32, 291.

[9] Fujii, Y. (2009) The Consideration of the Electromagnetic Wave in Dental Material Substitution. Acupuncture and Electro-Therapeutics Research, 34, 89. 
[10] Fujii, Y. (2012) Do Dental Implants Cause Scoliosis? Case Report. Personalized Medicine Universe, 1, 79-80. https://doi.org/10.1016/j.pmu.2012.05.012

[11] Fujii, Y. (2014) Gold Alloy Dental Inlay for Preventing Involuntary Body Movements Caused by Electromagnetic Waves Emitted by a Cell Phone. Open Journal of Antennas and Propagation, 2, 37-43. https://doi.org/10.4236/ojapr.2014.24005

[12] Fujii, Y. (2014) Sense of Balance Disorder Caused by Electromagnetic Waves Collected by a Dental Implant. Acupuncture and Electro-Therapeutics Research, 39, 379.

[13] Fujii, Y. (2014) Sensation of Balance Dysregulation Caused/Aggravated by a Collection of Electromagnetic Waves in a Dental Implant. Open Journal of Antennas and Propagation, 2, 29-35. https://doi.org/10.4236/ojapr.2014.23004

[14] Fujii, Y. (2015) Dental Treatment for Dizziness and Joint Mobility Disorder Caused by Harmful Electromagnetic Waves. Open Journal of Antennas and Propagation, 3, 1-7. https://doi.org/10.4236/ojapr.2015.31001

[15] Fujii, Y. (2015) Electromagnetic Waves Collected by a Dental Amalgam Filling Induced. Balance Dysregulation and Dizziness over a Period Exceeding 10 Years. Open Journal of Stomatology, 5, 235-242. https://doi.org/10.4236/ojst.2015.510029

[16] Fujii, Y. (2018) Hip Joint Pain Caused by Electromagnetic Waves Following an Operation for a Complex Humerus Fracture. Case Reports in Clinical Medicine, 7, 225-231. https://doi.org/10.4236/crcm.2018.73020

[17] Fujii, Y. (2014) A Case of Non-Allergenic Intractable Dermatitis Likely Caused by Mercury in Dental Amalgam. The Journal of Dentist, 2, 63-66. https://doi.org/10.12974/2311-8695.2014.02.02.4

[18] Fujii, Y. (2017) Severe Dermatitis Might Be Caused by a Cross-Reaction between Nickel and palladium and Dental Amalgam Resolved Following Removal of Dental Restoration. Clinical Case Reports, 5, 795-800. https://doi.org/10.1002/ccr3.938

[19] Omura, Y. (1993) Bi-Digital O-Ring Test for Imaging and Diagnosis of Internal Organs of a Patient. US Patent No. 5188107. http://academic.reed.edu/economics/parker/f11/354/pat/o-ring.pdf

[20] Bi-Digital O-Ring Test (BDORT). http://bdort.org/

[21] Fujii, Y. (2015) Calling into Question the Efficacy of Evidence-Based Medicine: Is It Always the Best Approach? Is That Really the Placebo Effect? Natural Science, 7, 165-170. https://doi.org/10.4236/ns.2015.74019

[22] Fujii, Y. (2015) Electromagnetic Waves and Indirect Effect. Don't You Believe Anything Which Isn't Visible? Lap Lambert Academic Publishing.

[23] Aalto, S., Haarala, C., Brück, A., Sipilä, H., Hämäläinen, H. and Rinne, J.O. (2006) Mobile Phone Affects Cerebral Blood Flow in Humans. Journal of Cerebral Blood Flow \& Metabolism, 26, 885-900. https://doi.org/10.1038/sj.jcbfm.9600279

[24] Haarala, C., Aalto, S., Hautzel, H., Julkunen, L., Rinne, J.O., Laine, M., Krause, B. and Hämäläinen, H. (2003) Effects of a $902 \mathrm{MHz}$ Mobile Phone on Cerebral Blood.

[25] Wolf, M., Haensse, D., Morren, G. and Froehlich, J. (2006) Do GSM 900MHz Signals Affect Cerebral Blood Circulation? A Near-Infrared Spectrophotometry Study. Optics Express, 14, 6128-6141. https://doi.org/10.1364/OE.14.006128 